\title{
Assessment of Nursing Students' Stress Levels and Coping Strategies During Their First Clinical Experience
}

\author{
Sebnem Bilgic ${ }^{1} \mathbb{D}$, Ulfiye Celikkalp ${ }^{2}$ \\ ${ }^{1}$ Trakya University, Faculty of Health Sciences, Fundamentals of Nursing Department, Edirne, Turkey. \\ ${ }^{2}$ Trakya University School of Medicine, Department of Public Health, Edirne, Turkey. \\ Correspondence Author: Sebnem Bilgic \\ E-mail: sebnembilgic@trakya.edu.tr \\ Received: $12.08 .2020 \quad$ Accepted: 06.08.2021
}

\begin{abstract}
Objective: This study was performed in order to examine the clinical stress levels of nursing students during their first clinical practice and their stress coping styles.

Methods: This descriptive study was performed with 91 freshmen in the nursing department of Namık Kemal University who experienced clinical practice for the first time. Data was collected using a student identification form, the clinical stress questionnaire and the stress-coping patterns scale.

Results: The students' mean age was $19.94 \pm 2.91$. The mean stress score of the students during their first clinical experience was found to be 29.16 \pm 7.92 . When the stress coping styles of the students were examined, their mean self-confidence approach score was $2.93 \pm 0.54$, their seeking social support score was $2.73 \pm 0.48$, their optimistic approach score was $2.68 \pm 0.61$, their helpless/self-accusatory approach score was $2.17 \pm 0.50$, and their submissive approach score was $1.84 \pm 0.44$.
\end{abstract}

Conclusion: The clinical stress levels of the students were found to be low and the students were found to use the confident approach most in coping with stress.

Keywords: Clinical stress, coping with stress, nursing student.

\section{INTRODUCTION}

Nursing education, which aims to cultivate nurses who can translate their skills and information into practice in a professional and proficient manner, encompasses clinical and theoretic education styles that complement each other (1). Clinical education, which is an essential part of nursing education, provides the student with the opportunity to apply the skills they have learned in a real world environment $(2,3)$. Thus, it helps the improvement of skills such as critical thinking, analysis, communication, and management among nursing students (4) in addition to knowledge, attitude, and values (5), providing the student with the opportunity to develop a professional identity $(2,6)$.

The first clinical experience, which signifies the beginning of professional life, is very important for nursing students (5). Positive integration into the health care environment motivates the student, provides positive opportunities for change and improvement, and helps the student stay in the profession. Besides this, a negative first clinical experience can be upsetting for students $(5,7)$ and cause stress $(8)$. During clinical practice, students can face many difficulties and challenges such as being in a dynamic and complicated environment, forming relationships with clinical staff and tutors, managing changes in patient status that constitute emergencies, and having to perform interventions on real people, and experience stress as a result (9-11).

In actuality, stress is an essential part of daily life and the natural reaction of the body to a situation perceived as involving physical and psychological danger (4). It was stated in the literature that although mild and medium levels of stress can have positive effects on the learning process of students, long term and intense stress experiences can have negative effects on clinical learning and health of the students, affecting patient care quality negatively $(3,9,12)$. These positive and negative effects of stress on individuals are actually related to an individual's ability to develop effective coping behaviors (13). An individual who can develop effective coping behaviors can easily adapt to a stressful situation, whereas an individual who develops ineffective coping behavior can experience worsened stress and increased adaptation problems $(4,14)$. In this context, 
development of effective stress coping behavior by nursing students is very important with regard to decreasing stress, allowing better performance, the formation of a professional identity, and the management of negative situations (1).

There are many studies in the literature examining clinical stress of nursing students. In the study by Shaban et al. (2012), nursing students experienced moderate levels of stress during clinical applications, using the problem-solving approach to cope with stress most (3). In Blomberg et al.'s (2014) study, more than half of the students were seen to experience severe stress during clinical practice (15). In studies performed in Turkey, nursing students were found to experience low $(14,16,17)$, moderate $(4,8)$, or high $(18)$ levels of stress during clinical practice. Alongside this, nursing students were found to mostly use the problem-oriented active style approach to coping with stress $(4,14,19)$.

Clinical practice is irrefutably important for nursing students. However, since the students enter an environment they are not used to and encounter many different situations, they may perceive their first clinical applications as a stressful situation. Additionally, if the students have developed appropriate stress coping approaches, they can easily cope with those stressful situations. For the clinical education of nursing students to reach its goal, it is thus very important to know the stress levels of nursing students during their first clinical practice and their stress coping behavior. For this reason, this study was performed in order to examine the clinical stress levels of nursing students during their first clinical practice and their stress coping styles.

\section{METHODS}

\subsection{Study Design}

The research was applied in a descriptive and correlational design.

\section{Research Questions:}

1. What is the stress level of freshmen nursing students during their first clinical experience?

2. What are the stress coping styles of freshmen nursing students?

3. What are the factors affecting the clinical stress level and coping styles of nursing students?

4. Is there a relationship between stress levels and stress coping styles of freshmen nursing students?

\subsection{Study Setting and Sample}

The universe of this study consisted of all freshmen $(n=102)$ studying in the nursing department of the health school of Namık Kemal University in the spring semester of the 20162017 academic year. The study included students who were in the first year of nursing, had no previous clinical experience, attended classes during the study period, and volunteered to participate in the study. Health vocational high school graduates were excluded from the study because they had previous clinical experience. The research was completed with 91 students who met the appropriate criteria.

\subsection{Instruments}

Data was collected using a Student Identification Form, the Clinical Stress Questionnaire (CSQ) and the Stress-coping Patterns Scale (SCPS).

The Student Identification Form: The form was prepared by the researcher and included five questions about age, sex, school of graduation, willingly choosing the nursing occupation, and whether there was a nurse in the family.

The Clinical Stress Questionnaire: The questionnaire was developed by Pagana (1989) to determine the initial value of stress that threatens or hinders nursing students in their first clinical experience. In the development of the 5-point Likert type self-report questionnaire, the cognitive evaluation of stress theory by Lazarus et al. was used. The 20 -item questionnaire is separated into four categories as threat ( 6 items), challenge ( 7 items), benefit ( 2 items), and harm ( 5 items). The score range of the questionnaire is $0-80$ and higher scores indicate higher stress levels. The Turkish validity and reliability study for the questionnaire was completed by Sendir and Acaroğlu (2006) and the Cronbach's alpha coefficient was found to be 0.70 (20). Cronbach's alpha coefficient was 0.70 in this study.

The Stress-Coping Patterns Scale (SCPS): The scale, which was developed by Folkman and Lazarus and tested for validity and reliability in Turkish by Sahin and Durak, is a 4-point Likert type scale with 30 items. The scale measures two main stress coping styles, namely problem-oriented effective methods (active style) and emotion-oriented ineffective methods (passive style) $(14,19,21)$. While efforts to remove the threatening event or decrease its effects are emphasized in problem-oriented coping, denial and avoidance are noted instead of fighting the stressful event in the emotion-oriented style (22). The self-confident approach (SCA), social support seeking approach (SSS), and optimistic approach (OA) sub dimensions are grouped under the active style, while the submissive approach (SA) and helpless/self-accusatory approach (HA) are grouped under the passive style. The scores for each sub dimension are calculated separately and higher scores indicate that the individual uses that style more when coping with stress $(14,19)$. The Cronbach alpha coefficients of the scales were determined to be $0.45-0.47$ for SSS, $0.49-0.68$ for OA, 0.62-0.80 for SCA, 0.64-0.73 for HA, and 0.47-0.72 for SA (19). In the present study, it was found Cronbach's alpha coefficients was 0.46 for SSS, 0.51 for OA, 0.81 for SCA, 0.72 for $\mathrm{HA}$, and 0.50 for $\mathrm{SA}$. 


\subsection{Data Collection}

Data was collected by the researchers at the end of the day following the first clinical experience of the students by handing the students the related forms, scales, and questionnaires in their classroom.

\subsection{Data Analysis}

Statistical analysis of the study data was performed in a computer environment using the SPSS 22.0 software with descriptive tests, comparative statistical methods (Mann Whitney $U$ test, Kruskal Wallis test), and the Pearson correlation analysis to determine the relationship between the scales.

\subsection{Ethical Considerations}

Before starting the study, approval was obtained from the Namık Kemal University Faculty of Medicine Non-Invasive Clinical Research Ethics Committee (2017/39/03/10) and written permission was obtained from the institution where the study will be conducted. Additionally, each student participating in the study was informed about the aim of the study, what was expected of them, their legal rights, and the confidentiality of the data obtained, and those who agreed to participate in the study provided written consent.

\section{RESULTS}

The mean age of the students participating in the study was $19.94 \pm 2.91$ years. It was found that $67.0 \%$ of the students were female, $53.8 \%$ were Science/Anatolian High School graduates, $63.7 \%$ chose the nursing occupation willingly, and $16.5 \%$ had nurses in their families.

The mean stress score of the students during their first clinical experience was found to be $29.16 \pm 7.92$ ( $\mathrm{min}=9$, $\max =48$ ). When the stress coping styles of the students were examined, their mean self-confident approach score was $2.93 \pm 0.54$ ( $\min =1.71, \max =4$ ), their seeking social support score was $2.73 \pm 0.48(\min =1.5, \max =3.7)$, their optimistic approach score was $2.68 \pm 0.61(\min =1.6, \max =3.4)$, their helpless/self-accusatory approach score was $2.17 \pm 0.50$ ( $\min =1.0, \max =3.0)$, and their submissive approach score was $1.84 \pm 0.44$ ( $\min =1.0, \max =3.0)$ (Table 1).

Nursing students graduating from Science/Anatolian High Schools used the submissive passive approach $(p=0.049)$ more to cope with stress, while those who chose the nursing occupation willingly used the active seeking social support approach ( $p=0.043$ ) more (Table 2 ).

Among nursing students, those graduating from other high schools received the highest score from the clinical stress total scale $(p=0.015)$, threat $(p=0.000)$, and harm $(p=0.041)$ sub dimensions. Students with nurses in their families received higher scores from the clinical stress sense of benefit ( $p=0.048$ ) sub dimension (Table 2 ).
When the relationship between the mean scores obtained from the two scales was examined, a high level positive correlation was found between the optimistic approach sub dimension and the sense of challenge $(r=0.827, p=0.000)$. A low level positive significant correlation was found between the self-confidence approach sub dimension and challenge ( $r=0.236, p=0.024)$, and a medium level positive significant correlation was found between benefit sub dimensions ( $r=0.361, p=0.000$ ). A low level of positive significiant correlation was found between the sub dimension of submissive approach and sense of threat $(r=0.241, p=$ $0.021)$ and harm ( $r=0.245, p=0.019)$. A negative significant correlation was found between the submissive approach sub dimension and the sense of benefit $(r=-0.297, p=0.004)$ (Table 3).

Table 1. Individual characteristics of participants $(n=91)$

\begin{tabular}{|c|c|c|c|}
\hline \multicolumn{2}{|l|}{ Characteristics } & $n$ & $\%$ \\
\hline \multirow[t]{2}{*}{ Gender } & Female & 61 & 67.0 \\
\hline & Male & 30 & 33.0 \\
\hline \multirow[t]{5}{*}{ Graduation School } & General High Schoo & 25 & 27.5 \\
\hline & Science/Anatolian & 49 & 53.8 \\
\hline & \multirow{2}{*}{$\begin{array}{l}\text { High School } \\
\text { Other High School }\end{array}$} & 17 & 18.7 \\
\hline & & & \\
\hline & $\begin{array}{l}\text { (Technical and } \\
\text { Religious) }\end{array}$ & & \\
\hline \multirow{3}{*}{ Willingly choosing nursing } & \multirow{2}{*}{ Yes } & & 627 \\
\hline & & 58 & 63.7 \\
\hline & No & 33 & 36.3 \\
\hline \multirow[t]{2}{*}{ Having a nurse in the family } & \multirow{2}{*}{$\begin{array}{l}\text { Yes } \\
\text { No }\end{array}$} & 15 & 16.5 \\
\hline & & 76 & 83.5 \\
\hline & \multicolumn{2}{|l|}{ Mean \pm SD } & (min-max) \\
\hline Age, (years) & \multicolumn{2}{|l|}{$19.94 \pm 2.91$} & $18-34$ \\
\hline Total CSQ & \multicolumn{2}{|l|}{$29.16 \pm 7.92$} & $9-48$ \\
\hline Threat (6 items) & \multicolumn{2}{|l|}{$6.60 \pm 3.99$} & $0-19$ \\
\hline Challenge (7 items) & \multicolumn{2}{|l|}{$15.46 \pm 5.60$} & $0-25$ \\
\hline Harm (5 items) & \multicolumn{2}{|l|}{$2.93 \pm 3.18$} & $0-15$ \\
\hline Benefit (2 items) & \multicolumn{2}{|l|}{$4.19 \pm 2.09$} & $0-8$ \\
\hline
\end{tabular}

\begin{tabular}{lcc}
\hline Stress-Coping Patterns & & \\
\hline Self-confident approach & $2.93 \pm 0.54$ & $1.71-4$ \\
\hline Seeking social support & $2.73 \pm 0.48$ & $1.5-3.7$ \\
\hline Optimistic approach & $2.68 \pm 0.61$ & $1.6-3.4$ \\
\hline Helpless/self-accusatory approach & $2.17 \pm 0.50$ & $1.0-3.0$ \\
\hline Submissive approach & $1.84 \pm 0.44$ & $1.0-3.0$ \\
\hline
\end{tabular}


Table 2. CSQ and SCPS mean scores according to socio-demographic characteristics of participants ( $n=91$ )

\begin{tabular}{|c|c|c|c|c|c|c|c|c|c|c|}
\hline \multirow{3}{*}{ Characteristics } & \multirow[b]{3}{*}{ Threat } & \multirow[b]{3}{*}{ Challenge } & \multirow{3}{*}{ CSQ } & \multirow[b]{3}{*}{ Benefit } & \multirow[b]{3}{*}{ Total } & \multicolumn{5}{|c|}{ SCPS } \\
\hline & & & & & & \multicolumn{3}{|c|}{$\begin{array}{c}\text { Problem-oriented/active } \\
\text { patterns }\end{array}$} & \multicolumn{2}{|c|}{$\begin{array}{c}\text { Emotion-oriented/ } \\
\text { passive patterns }\end{array}$} \\
\hline & & & & & & $\begin{array}{l}\text { Optimistic } \\
\text { approach }\end{array}$ & $\begin{array}{c}\text { Self- } \\
\text { confident } \\
\text { approach }\end{array}$ & $\begin{array}{l}\text { Seeking } \\
\text { social } \\
\text { support }\end{array}$ & $\begin{array}{c}\text { Helpless/ } \\
\text { self- } \\
\text { accusatory } \\
\text { approach }\end{array}$ & $\begin{array}{c}\text { Submissive } \\
\text { approach }\end{array}$ \\
\hline \multicolumn{11}{|l|}{ Gender } \\
\hline Female & $6.96 \pm 4.29$ & $15.77 \pm 5.28$ & $2.93 \pm 3.11$ & $4.14 \pm 2.08$ & $29.81 \pm 7.41$ & $2.60 \pm 0.66$ & $2.85 \pm 0.53$ & $2.71 \pm 0.46$ & $2.23 \pm 0.52$ & $1.83 \pm 0.46$ \\
\hline Male & $5.86 \pm 3.23$ & $14.84 \pm 6.26$ & $2.93 \pm 3.39$ & $4.30 \pm 2.15$ & $27.93 \pm 8.87$ & $2.85 \pm 0.47$ & $3.08 \pm 0.52$ & $2.76 \pm 0.55$ & $2.08 \pm 0.46$ & $1.85 \pm 0.42$ \\
\hline$p^{*}$ & 0.130 & 0.339 & 0.811 & 0.902 & 0.212 & 0.262 & 0.545 & 0.425 & 0.302 & 0.576 \\
\hline \multicolumn{11}{|l|}{ Graduate School } \\
\hline General HS ${ }^{1^{x}}$ & $4.28 \pm 2.71$ & $15.80 \pm 5.14$ & $1.80 \pm 1.77$ & $4.72 \pm 1.64$ & $26.60 \pm 6.98$ & $2.65 \pm 0.44$ & $2.97 \pm 0.43$ & $2.68 \pm 0.55$ & $2.11 \pm 0.45$ & $1.66 \pm 0.41$ \\
\hline Science/Anatolian & $6.85 \pm 3.56$ & $15.14 \pm 5.81$ & $3.04 \pm 3.40$ & $3.93 \pm 2.27$ & $28.95 \pm 8.26$ & $2.64 \pm 0.47$ & $2.90 \pm 0.57$ & $2.77 \pm 0.48$ & $2.19 \pm 0.51$ & $1.93 \pm 0.43$ \\
\hline $\mathrm{HS}^{*}$ & $9.20 \pm 4.92$ & $15.94 \pm 5.92$ & $4.29 \pm 3.68$ & $4.17 \pm 2.12$ & $33.70 \pm 6.54$ & $2.87 \pm 1.06$ & $2.94 \pm 0.60$ & $2.70 \pm 0.42$ & $2.22 \pm 0.59$ & $1.83 \pm 0.47$ \\
\hline Others HS (technical & 0.000 & 0.824 & 0.041 & 0.321 & 0.015 & 0.404 & 0.869 & 0.734 & 0.746 & 0.049 \\
\hline $\begin{array}{l}\text { and religious })^{*} \\
p^{* *}\end{array}$ & $3>1-2$ & & $3>1$ & & $3>1$ & & & & & $2>1$ \\
\hline \multicolumn{11}{|l|}{ Willing choice nursing } \\
\hline Yes & $5.36 \pm 3.32$ & $16.43 \pm 5.04$ & $2.20 \pm 2.80$ & $4.56 \pm 2.01$ & $28.56 \pm 7.17$ & $2.74 \pm 0.48$ & $3.03 \pm 0.50$ & $2.74 \pm 0.43$ & $2.10 \pm 0.48$ & $1.79 \pm 0.44$ \\
\hline No & $8.78 \pm 4.18$ & $13.75 \pm 6.20$ & $4.21 \pm 3.46$ & $3.54 \pm 2.10$ & $30.30 \pm 9.11$ & $2.58 \pm 0.79$ & $2.74 \pm 0.55$ & $2.72 \pm 0.59$ & $2.29 \pm 0.52$ & $1.91 \pm 0.45$ \\
\hline p* & 0.197 & 0.087 & 0.071 & 0.655 & 0.053 & 0.560 & 0.583 & 0.043 & 0.536 & 0.971 \\
\hline \multicolumn{11}{|c|}{ Having a nurse in your family } \\
\hline Yes & $6.80 \pm 4.93$ & $16.20 \pm 3.93$ & $2.86 \pm 2.13$ & $4.93 \pm 1.57$ & $30.80 \pm 7.15$ & $2.72 \pm 0.60$ & $3.00 \pm 0.55$ & $2.73 \pm 0.35$ & $2.16 \pm 0.44$ & $1.91 \pm 0.49$ \\
\hline No & $6.50 \pm 3.82$ & $15.31 \pm 5.89$ & $2.94 \pm 3.37$ & $4.05 \pm 2.16$ & $28.88 \pm 8.07$ & $2.68 \pm 0.62$ & $2.91 \pm 0.53$ & $2.73 \pm 0.51$ & $2.18 \pm 0.52$ & $1.82 \pm 0.43$ \\
\hline$p^{*}$ & 0.504 & 0.066 & 0.245 & 0.048 & 0.850 & 0.561 & 0.796 & 0.189 & 0.385 & 0.510 \\
\hline
\end{tabular}

*High School, *Mann Whitney U test was used. ** Kruskal Wallis test was used. Statistically significant values (p <0.05) are shown in bold.

Table 3. The relationship between the clinical stress level of participants and their ways of coping with stress

\begin{tabular}{|c|c|c|c|c|c|c|}
\hline SCPS & CSQ & Threat & Challenge & Harm & Benefit & Total \\
\hline \multirow{2}{*}{$\begin{array}{l}\text { Optimistic } \\
\text { approach }\end{array}$} & $r$ & 0.087 & 0.827 & -0.066 & 0.187 & 0.083 \\
\hline & $p$ & 0.410 & 0.000 & 0.536 & 0.076 & 0.437 \\
\hline \multirow{2}{*}{$\begin{array}{l}\text { Self-confident } \\
\text { approach }\end{array}$} & $r$ & -0.171 & 0.236 & -0.047 & 0.361 & 0.158 \\
\hline & $\mathrm{p}$ & 0.106 & 0.024 & 0.659 & 0.000 & 0.135 \\
\hline \multirow{2}{*}{$\begin{array}{l}\text { Seeking social } \\
\text { support }\end{array}$} & $r$ & -0.101 & 0.124 & -0.159 & 0.068 & 0.009 \\
\hline & $p$ & 0.339 & 0.241 & 0.132 & 0522 & 0.931 \\
\hline \multirow{2}{*}{$\begin{array}{l}\text { Helpless/self- } \\
\text { accusatory } \\
\text { approach }\end{array}$} & $r$ & 0.201 & 0.085 & 0.166 & -0.193 & 0.057 \\
\hline & p & 0.056 & 0.424 & 0.166 & 0.067 & 0.591 \\
\hline \multirow{2}{*}{$\begin{array}{l}\text { Submissive } \\
\text { approach }\end{array}$} & $r$ & 0.241 & -0.151 & 0.245 & -0.297 & 0.035 \\
\hline & $p$ & 0.021 & 0.154 & 0.019 & 0.004 & 0.742 \\
\hline
\end{tabular}

Pearson Correlation test was used. Statistically significant values $(p<0.05)$ are shown in bold.

\section{DISCUSSION}

Clinical education is the most important learning experience for nursing students where they translate the knowledge and skills they gain during theoretical education into practice. Clinical practice environments, despite being inevitable for the improvement of the professional skill and knowledge of students, also constitute an important source of anxiety and stress $(9,11,23)$. Nursing students' experience with clinical practice may have profound effects on their desire to study nursing as well as their approach to clinical situations. Students' coping with stress in their first clinical experience will also affect the quality of nursing education (24). The factors that create the most stress for students during clinical practice were stated to be clinical stressors (lack of occupational skill and knowledge, communication with patients and clinical personnel etc.) $(10,18)$ and academic stressors (clinical exams, communication with lecturers etc.) $(9,11)$.

In this study that was conducted to determine stress experienced by nursing students in their first clinical applications and their stress coping styles, students were generally found to have low levels $(29.16 \pm 7.92)$ of clinical stress. This finding answers the first question of the study. Similar to these findings, low levels of perceived clinical stress were reported in other studies as well $(14,16,17)$. In the literature, a low level of clinical stress was reported to be desirable because of its stimulating effect, contributing to the creation of a safe learning environment for the student and an increase in academic success $(11,16,25)$. Alongside this, low levels of clinical stress may provide the opportunity for better evaluation of patient needs by the student, as well as for better communication with patients and next of 
kin, helping clinical education reach its goal (26). The study also demonstrated that average scores in sub-di mensions of clinical stress questionnaire were the highest in challenge and the lowest in harm emotions. This shows that clinical practice is perceived as a low level of harm for the student and increases the student's sense of challenge. Similar results were reported in various studies $(8,14,26)$. In a study by Atay and Yilmaz (2011), students reported higher levels of clinical stress with their sense of threat and harm (18). In Tambağ's study, it was reported that the anxiety level of students who went into clinical practice for the first time was high (27). In another study, it was reported that students experienced moderate anxiety before clinical practice (28). The low level of clinical stress found among the students in this study may be caused by the curriculum supporting the student, not much responsibility being given to students on their first clinical day, and adaptation to the hospital environment and personnel being emphasized.

Groups who are under more stress because of their working conditions and work environment need to have effective (active) coping behavior. Developing effective stress coping skills in individuals not only protects their bodily and mental health and their relationships with their environment, but also directly affects the lives of those for whom they provide care (29). In other studies, nursing students were found to mostly use a self-confident approach as well $(9,19,26)$. In a study by Chan et al (2009), students with low stress levels were found to use active styles in coping with stress (11). In a study conducted by Al-Gamal et al (2018) in Arabia, nursing students were stated to mostly use the problem-solving strategy to cope with stress (9). In another study, the selfconfident approach in coping with stress was found to be related to lower stress levels and the situation adaptation indicator (30). In this study, nursing students were found to mostly use a self-confident approach for coping with stress, thus using an active style. These results also answer the second question of the study.

In the study some demographic variables affecting clinical stress levels of students and their stress coping styles were studied. In this scope, it was determined that gender of students did not make any difference in terms of stress levels of students and their coping style with stress. Karagözoğlu et al. (2013) found that gender did not affect the clinical stress level of nursing students (26). Similarly, in Taşdelen and Zaybak's (2013) study examining the stress level of nursing students in their first clinical experience, it was determined that gender did not affect the clinical stress level of students (8). Other studies indicated that female students experience higher levels of stress than male students (31, 32) and presented as reasons of this difference, expression of emotions and anxieties more by women than men and gender differences in psychological morbidity (31). The fact that no significant differences were established in this study was considered to be a positive finding.

In the country where the study was carried out, there are high schools such as Science high schools, Anatolian high schools, General high schools, Technical high schools, and Religious high schools. Students are admitted to these schools through examinations organized by the Ministry of Education and only students with high scores are accepted to science high schools and Anatolian high schools. In technical high schools and religious high schools, vocational courses are given more importance. In the study, a significant difference was found between the total scores for clinical stress and the mean scores for threat and harm subscales according to the schools the students graduated from. Especially, the stress levels of students who graduated from other high schools (Technical high school, Religious high school) were higher. Graduates from other high schools perceived clinical practice as more threatening and harmful to themselves. This situation is thought to be due to the fact that students come from different educational backgrounds and their academic achievement and awareness are low. When clinical stresses and coping styles of students were assessed according to high schools they graduated from, it was determined that graduates of Science/Anatolian high schools used passive submissive tendency more than general high school graduates. While there were no other studies in the literature supporting this finding, it was noted that students with higher academic successes displayed better coping behaviors (active style approach). It was considered that results of this study could be based on different factors such as the fact that Science/Anatolian high school graduates choose studying nursing unwillingly, they did not like the vocation, and that the vocation fail to meet expectations of these students.

In the study, no significant difference was found between the clinical stress scores of the students who willingly chose nursing. Study by Ergin et al. noted that most of the students choose studying nursing willingly and no relationship could be established between their willingly choosing the vocation and their stress levels (33). In Findik et al.'s study to measure the clinical stress of the students prior to practice in the operating room, choosing the nursing profession voluntarily did not affect the clinical stress level of the students (14). In another similar study, the voluntary choice of nursing did not affect the stress level (34). However, students who willingly chose nursing used more active social support in coping with stress. Requesting social support is asking for assistance by individuals from their close circles and their acceptance of support received (35). Help from the social environment in coping with stress helps stress to be tolerated more easily and coped with better $(35,36)$. The fact that students who chose nursing willingly had higher social support scores suggests that these students may have received support from individuals in their environment when they chose their occupation. Similar to this finding, study by Yilmaz et al. and study by Okuyan and Deveci found that requesting social support had a higher score among students that choose to study nursing willingly (37-38).

In this study, students with nurses in their families were found to receive higher scores from the clinical stress sense of benefit sub dimension. This result shows that those who work 
as nurses in the family constitute positive examples and a good support system in the selection of the nursing occupation. It was also determined that the willingness to choose nursing did not affect coping with stress. Study by Durmuş and Gerçek found that having nurses in the family decreased stress scores (39). Study by Topal Hançer et al. (2019) also found lower stress scores for students with nurses in the family and argued that this was based on choice of students this vocation knowingly, being familiar with its structure (40). These results answered the third question of the study.

Although the first clinical experience is more or less stressful for every student, people can have different styles of coping with stress. Nursing students who used the active style optimistic approach and the self-confident approach more saw their first clinical experience as more of a challenge and beneficial to themselves. Alongside this, nursing students who used the passive style submissive approach more saw their first clinical experience as more of a threat and harmful to themselves, and less beneficial. Study by Evgin et al. (2017) that discussed student anxieties in pre-clinical application period argued that students with high levels of anxiety used silent coping methods when faced with stressful situations (41). Another study determined that as stress levels increase in students, they tend to use passive style stress coping mechanisms such as avoidance more (40). Study by Fındık et al. found that stress levels experienced by students affected their coping styles and that students with low stress levels used active styles while individuals with high stress levels used passive styles in coping with stress (14). Another study by Karaca et al. described that as level of perceived stress increase in nursing students, they use avoidance as coping mechanism more (31). In a study conducted with psychiatric nursing students, Tully (2004) found that students with higher stress levels used negative behavioral patterns such as smoking, consuming alcohol, using drugs, or forgetting about the situation more than active coping methods for coping with stress (30). This study argued that employment of effective coping mechanisms by students demonstrated such methods affect stress levels positively. According to these findings, we think that students who developed active styles for coping with stress saw their first clinical experience as more positive and contributing to their learning. With these results, the fourth question of the study was also answered.

\section{Limitations and strengths of the study}

The study had some limitations. Data from the study was limited with one health school. Thus, data cannot be generalized to all nursing schools. There are similar studies in Turkey, however, this study achieved different results. In addition, a significant strength of this study was its being the first study assessing clinical trainings of students while the school where this study was conducted was an established school giving nursing education for almost thirty years. In this scope, the study was expected to be assessed before clinical training period which was an indispensable part of nursing vocation, to guide training processes before and during clinical training provided by trainers, and to contribute to the literature.

\section{CONCLUSION}

As a result of this study it was determined that nursing students who had their first clinical application experience had low stress levels and that they used active stress coping styles more frequently. Low stress level and high use of selfconfidence approach were findings that supported each other in the study. In addition, employment of active styles by students proved that they could effectively cope with stress. Positive results were considered to be a pleasing/ hopeful property for nursing training. However, because training is a dynamic process, academics must always assume duties and responsibilities while nursing students recognize such stresses and develop skills to cope with stress. Nurse academics can reinforce student nurses starting from their academic lives to contribute to development of both students and the vocation.

\section{Conflict of Interest: None}

Financial Disclosure: There is no external funding.

Acknowledgement: This study was presented as an oral presentation at the 1 st International Health Sciences Congress 2017 Edirne. We thank all the students who participated in this study.

\section{REFERENCES}

[1] Khater W, Akhu-Zaheya L, Shaban I. Sources of stress and coping behaviours in clinical practice among baccalaureate nursing students. Int. J. Human. Soc. Sci. Res. 2014; 4(6): 194-202.

[2] Asadizaker M, Abedi ZH, Alijanirenani H, Moradi M, Jahani S. Improvement of the first training for baccalaureate nursing students -a mutual approach. Glob. J. Health Sci 2015; 7(7): 79-92.

[3] Shaban IA, Khater WA, Akhu-Zaheya LM. Undergraduate nursing students' stress sources and coping behaviours during their initial period of clinical training: A Jordanian perspective. Nurse Educ. Pract. 2012; 12(4): 204-209.

[4] Karabacak Ü, Uslusoy E, Şenturan L, Alpar ŞE, Yavuz D. First day in clinical practice: evaluating stress of nursing students and their ways to cope with it. HealthMED 2012; 6(2): 596-602.

[5] Levett-Jones T, Pitt V, Courtney-Pratt H, Harbrow G, Rossiter $R$. What are the primary concerns of nursing students as they prepare for and contemplate their first clinical placement experience?. Nurse Educ. Pract. 2015; 15(4); 304-309.

[6] O'Mara L, McDonald J, Gillespie M, Brown H, Miles L. Challenging clinical learning environments: Experiences of undergraduate nursing students. Nurse Educ. Pract. 2014; 14(2): 208-213.

[7] Cooper J, Courtney-Pratt H, Fitzgerald M. Key influences identified by first year undergraduate nursing students as impacting on the quality of clinical placement: A qualitative study. Nurse Educ. Today 2015; 35(9): 1004-1008.

[8] Tasdelen S, Zaybak A. The determination the level of stress of nursing students during their first clinical experience. Florence Nightingale J Nurs 2013; 21(2): 101-106.

[9] Al-Gamal E, Alhosain A, Alsunaye K. Stress and coping strategies among Saudi nursing students during clinical education. Perspect Psychiatr Care 2018; 54:198-205. 
[10] Al-Zayyat AS, Al-Gamal E. Perceived stress and coping strategies among Jordanian nursing students during clinical practice in psychiatric/mental health courses. Int J Ment Health Nurs 2014; 23(4): 326-335.

[11] Chan CKL, So WKW, Fong DYT. Honk Kong baccalaureate nursing students' stress and their coping strategies in clinical practice. J Prof Nurs 2009; 25: 307-313.

[12] Lee MH, Holzemer WL, Faucett J. Psychometric evaluation of the Nursing Stress Scale (NSS) among Chinese nurses in Taiwan. J. Nurs. Meas. 2007; 15(2): 133.

[13] Pulıdo-Martos M, Augusto-Landa JM. Lopez-Zafra E. Sources of stress in nursing students: a systematic review of quantitative studies. Int Nurs Rev 2012; 59: 15-25.

[14] Findik ÜY, Ozbas A, Cavdar I, Topcu SY, Onler E. Assessment of nursing students' stres levels and coping strategies in operating room practice. Nurse Educ. Pract. 2015; 15: 192-195.

[15] Blomberg K, Bisholt B, Kullén Engström A, Ohlsson U, Sundler Johansson A, Gustafsson M. Swedish nursing students' experience of stress during clinical practice in relation to clinical setting characteristics and the organisation of the clinical education. J. Clin. Nurs. 2014; 23(15-16): 2264-2271.

[16] Acıksoz S, Uzun Ş, Arslan F. Assessment of relationship between nursing students' self-efficacy and levels of their anxiety and stress about clinical practice. Gulhane Med J 2016; 58: 129-135.

[17] Potur DC, Bilgin NÇ, Komurcu N. Evaluating nursing students clinic stress, and coping with stress during the clinic first day of the woman health and diseases nursing clinical course. International Journal of Human Sciences 2015; 12(1):11691181.

[18] Atay S, Yilmaz F. The First stress levels of the students of vocational higher school of healt. Journal of Anatolia Nursing and Health Sciences 2011; 14 (4): 32-37.

[19] Temel E, Bahar A, Cuhadar D. Determination of coping attitude with stress and depression level of nursing students. Journal of Firat Health Services 2007; 2: 108-118.

[20] Sendir M, Acaroglu, R. Reliability and validity of Turkish version of clinical stress questionnaire. Nurse Educ. Today 2008; 28: 737-743.

[21] Hampel P, Petermann F. Perceived stress, coping, and adjustment in adolescents. J. Adolesc. Health 2006; 38(4): 409-415.

[22] Turkum AS. The Development of coping with stress scale: validity and reliabilty studies. Turkish Psychological Counseling and Guidance Journal 2016; 2(18): 25-34.

[23] Nelwati D, McKenna L, Plummer V. Indonesian student nurses' perceptions of stress in clinical learning: A phenomenological study. J Nurs Educ Pract. 2012; 3(5): 56-65.

[24] Sheu S, Lin HS, Hwang SL. Perceived stress and physio-psychosocial status of nursing students during their initial period of clinical practice: the effect of coping behaviors. Int. J. Nurs. Stud. 2002; 39(2): 165-175.

[25] Melincavage SM. Student nurses' experiences of anxiety in the clinical setting. Nurse Educ. Today 2011; 31(8): 785-789.

[26] Karagözoğlu Ş, Özden D, Tok Yıldız F. Clinical stress levels of nursing students participating in an integrated program and the factors affecting the levels. Journal of Anatolia Nursing and Health Sciences 2013; 16(2): 89-95.

[27] Tambağ H. Examination of nursing students' anxiety levels related to clinical practice with respect to peer support. Perspect Psychiatr Care. 2020. DOI: 10.1111/ppc.12664

[28] Tosunöz iK, Güngör S, Öztunç G. The anxıety before fırst clınıcal experience: the case of nursing students. YOBU Faculty of Health Sciences Journal. 2021; 2 (1): 54-61

[29] Zhao FF, Lei XL, He W, Gu YH, Li DW. The study of perceived stress, coping strategy and self-efficacy of Chinese undergraduate nursing students in clinical practice. Int. J. Nurs. Pract. 2015; 21. 401-409.

[30] Tully A. Stress, sources of stress andways of coping among psychiatric nursing students. J. Psychiatr. Ment. Health Nurs. 2004; 11: 43-47.

[31] Karaca A, Yıldırım N, Ankaralı H, Açıkgöz F, Akkuş D. Nursing students' perceived levels of clinical stress, stress responses and coping behaviors. J. Psychiatr. Nurs. 2017; 8(1): 32-39.

[32] Özdemir H, Khorshıd L, Zaybak A. Determination of nursing students' stress level toward nursing education. Turkish Journal of Science and Health. 2020; 1(2): 20-28.

[33] Ergin E, Çevik K, Pakiş Çetin S. An Investigation of nursing students' perceptions and coping behaviors of educationrelated stress. Journal of Education and Research in Nursıng. 2018; 15(1): 16-22.

[34] Büyükbayram Z, Ayık DB. Determination of nursing students' stress levels related to nursing education. Journal of Adnan Menderes University Health Sciences Faculty. 2020; 4(2): 90-99.

[35] Üstündağ H, Bostancı Z, Aydoğan B. Relationship between coping style with stress and the levels of perceived social support among nursing students. Journal of Health Sciences and Professions. 2019; 6(1): 74-83.

[36] Yamac Ö. The relationship between perceived social support and stress coping styles of university students. Doctoral dissertation, Selcuk University Institute of Social Sciences, 2009. Konya.

[37] Yılmaz M, Yaman Z, Erdoğan S. Stressful situation in nursing students and the methods of coping with stress. Mersin University Journal of Health Sciences. 2017; 10(2): 88-99.

[38] Okuyan CB, Deveci E. The methods for coping with stress and stress situations of nursing students in health school. Journal of Anatolia Nursing and Health Sciences. 2020; 23(2): 205-211.

[39] Durmuş ÖGM, Gerçek ÖGA. A research on assessıng the factors affectıng perceived stress sıtuatıons, bı--psychologıcal social situations and copıng behaviors of stress in university students'. The Journal of Academic and Social Science. 2017; 5(53);616-633.

[40] Topal Hançer A, Güler N, Süha BK. Nursing senior students' perceived stress and stress coping behaviors. J Nurs Sci. 2019; 11(4): 347-356

[41] Evgin D, Çalışkan ZI, Caner N. Anxıety levels and strategıes for copıng with stress of nursıng students at health college bef1ore clınıcal practıce. SDÜ Journal of Health Sciences. 2017; 8(3): 22-28. 